Revista

Ibero-Americana

de Estratégıa

\author{
INOVAÇÃO E MODELO DE NEGÓCIO - UM ESTUDO DE CASO NO SETOR \\ VITIVINICULTOR
}

\title{
INNOVATION AND BUSINESS MODEL - A CASE STUDY IN SECTOR VINTNER
}

\section{INNOVACIÓN Y MODELO DE NEGOCIO - UN ESTUDIO DE CASO EN VITICULTOR SECTOR}

\section{Leonel Cezar Rodrigues}

Doutor em Administração Universitária pela Vanderbilt University, Estados Unidos

Coordenador do Programa de Doutorado Interinstitucional em Administração da Universidade Nove de Julho - DINTER/UNINOVE

E-mail: leonel@uninove.br (Brasil)

\section{Amelia Silveira}

Doutora em Ciências da Comunicação pela Universidade de São Paulo - USP

Professora do Programa de Pós-Graduação em Administração da Universidade Nove de Julho PPGA/UNINOVE

E-mail: amelia@uninove.br (Brasil)

\section{Carlos Mamori Kono}

Mestre em Administração pela Universidade Nove de Julho - UNINOVE

Diretor do Sistec Sistemas e Tecnologia Informatica Ltda

E-mail: carloskono@ sistec.net.br (Brasil)

\section{Fernando Cesar Lenzi}

Doutor em Administração pala Faculdade de Administração, Economia e Contabilidade da Universidade de São Paulo - FEA/USP

Professor da Universidade do Vale do Itajaí - UNIVALI

E-mail: lenzi@univali.br (Brasil) 


\section{INOVAÇÃO E MODELO DE NEGÓCIO - UM ESTUDO DE CASO NO SETOR VITIVINICULTOR}

\section{RESUMO}

A pesquisa objetivou determinar quais as inovações e sua respectiva natureza, que determinaram a estratégia configurante do modelo de negócios da Casa Valduga, tradicional produtora de vinhos, e que tem lhe estimulado a exceder na qualidade de seus produtos, ampliando seu mercado nacional e expandindo-se internacionalmente. $\mathrm{O}$ estudo tem abordagem exploratória e qualitativa, buscando analisar o fenômeno em questão coletando dados a partir de entrevistas, documentos e observação. Conclui-se que o modelo de negócio adotado origina-se no ajuste fino dos recursos da empresa com seus interesses de segmentação mercadológica, na capacidade para a geração de produtos de qualidade superior, integrantes de seu portfólio de produtos e no controle estratégico de atributos de valor ligados à imagem e marca da empresa.

Palavras-chave: Estratégia Competitiva; Estratégia Corporativa; Inovação; Modelo de Negócio.

\section{INNOVATION AND BUSINESS MODEL - A CASE STUDY IN SECTOR VINTNER}

\section{ABSTRACT}

This research targeted at determining type and nature of innovation associated to the curbing strategies of the business model at Casa Valduga, a traditional Brazilian wine producer that has stimulating that house to exceed in product quality, expanding its domestic and international market. The research was designed to explore, qualitatively, the phenomenon gathering data through interviews, formal documentation checking and observation. One conclude that the adopted business model originates basically from the company's corporate strategies, to appropriate resources, capacities and competences, than from a common competitive intended strategy. Corporate strategy is based on fine tuning of the company's resources with market segment interest. Corporate strategy help adjust capacity to generate superior quality products with the strategic control of value attributes, linked to the image and trademark of the company.

Keywords: Competitive Strategy; Corporate Strategy; Innovation; Business Model. 
Leonel Cezar Rodrigues, Amelia Silveira, Carlos Mamori Kono \& Fernando Cesar Lenzi

INNOVACIÓN Y MODELO DE NEGOCIO - UN ESTUDIO DE CASO EN VITICULTOR SECTOR

\section{RESUMEN}

La investigación tuvo como objetivo determinar cuáles son las innovaciones y su naturaleza respectiva, que determinan la estrategia de la empresa modelo configurante Casa Valduga, productor tradicional de vino, y ha animado a superar la calidad de sus productos, la expansión de su mercado interno y la expansión internacionalmente. El estudio es el enfoque exploratorio y cualitativo, que busca analizar el fenómeno en cuestión recogiendo datos de entrevistas, documentos y observación. Llegamos a la conclusión de que el modelo de negocio adoptado origina en afinar los recursos de la compañía para sus intereses segmentación marketing, la capacidad de generar productos de alta calidad, la integración de su portafolio de productos y atributos de control estratégicos valor relacionado con la imagen y la marca de la compañía.

Palabras-clave: Estrategia Competitiva; Estrategia Empresarial; Innovación; Modelo de Negocio. 


\section{INTRODUÇÃO}

A era da inovação como fonte de renovação e de capacidade competitiva das empresas começa a se delinear como o paradigma que fundamenta a concepção de negócios competitivos. Há dois focos essenciais de atenção da inovação. O primeiro foco está voltado para inovação em produtos, entendido em seu sentido mais amplo e envolvendo serviços como objeto de troca. Outro é de inovação no modelo de negócio. A premissa neste último caso é de que para competir bem, as empresas precisam revolucionar a forma de conceber seus negócios. Hamel (2000) e Hagel III (2002) já apontavam, no início da década, a importância de uma nova lógica de modelagem dos negócios: a de que a estratégia somente não seria mais suficiente para dar sustentabilidade a negócios vencedores. Para os autores, construir negócios vencedores significa enveredar por caminhos alternativos na forma de gerir os atributos de valor que fundamentam a construção e o acesso a bens e serviços. Tais ideias estão estreitamente ligadas à centralidade da inovação como fundamento do modelo e da flexibilização dos processos de negócio.

De onde viria, porém, todo o peso deste novo paradigma para os negócios? As respostas estão na modificação gradativa e irreversível dos elementos comuns que fazem parte do entorno de todos os negócios, o ciclo de vida das tecnologias, dos produtos e dos mercados. Tecnologias servem a processos e produtos durante períodos cada vez menores e então precisam ser substituídas. Produtos possuem uma elasticidade à demanda, associada a desenho, tecnologia, desempenho ou funcionalidade, por períodos também cada vez menores. Perdem força de vendas e então precisam ser redesenhados, remodelados ou substituídos. Na mesma linha e pelos mesmos motivos, mercados e segmentos de mercado se mantém lucrativamente atrativos para serem explorados, por períodos menores e da mesma forma, tornam-se rapidamente desinteressantes para as empresas.

O resultado evidente é que o entorno competitivo e as circunstâncias transacionais estrangulam a eficácia dos modelos tradicionais de negócio e remetem as empresas à cata de novos modelos. Em geral, o entorno e as circunstâncias são os grandes definidores dos modelos. Quando a empresa define seus objetivos de participação mercadológica e lucratividade olhando essencialmente as oportunidades existentes em seu entorno, então modela seu negócio com base no posicionamento possível e desejado em seu mercado de atuação, de fato ela estará combinando suas competências internas, por meio de ajuste preliminar e contingencial de sua estratégia corporativa.

No caso selecionado, a Casa Valduga é uma bodega de elaboração de vinhos, estabelecida desde 1875, com as primeiras imigrações de italianos na serra gaúcha. Originalmente voltada para o plantio de uvas de alto rendimento por área plantada e, portanto, voltada para a produção quase 
exclusiva de sucos, a Casa Valduga tem se notabilizado, nos últimos 20 anos pela qualidade de seus vinhos, hoje de alcance internacional e excelência de seus sucos e champanhes. As inovações na Casa, porém, aconteceram nesta última geração, onde a qualidade e excelência de seus produtos, tanto a de sucos quanto a de vinhos, começou a ocupar a mente de seu principal executivo e dono. As inovações em seu negócio projetaram a Casa Valduga, como empresa, no âmbito do mercado nacional e internacional.

$\mathrm{O}$ ajuste em sua forma de transacionar quer olhando primeiramente seu entorno, quer olhando seus recursos e capacidades para definir seu modelo de negócio. Desta forma procura entender a inovação no âmbito das estruturas, funções e arranjos nesta organização, assim como estudar a inovação e os modelos de negócio. A eficiência ou eficácia dos ajustes é normalmente, uma função do grau de inovação em seus processos de negócio. Em qualquer caso, no entanto, a empresa estará às voltas com a necessidade de inovar, não necessariamente em seus produtos, mas definitivamente em seus processos administrativos e de interface com seu mercado.

Um modelo de negócio se caracteriza essencialmente pelo arranjo dos recursos, capacidades e competências internas visando criar e capturar valor. Ora, isso implica a conformação e ênfase no uso e distribuição dos elementos que suportam as estratégias competitivas, corporativas e organizacionais. Por exemplo, um modelo de negócio com ênfase em recursos e com uma estrutura mecanicista, visando à expansão de sua posição específica de participação no mercado, difere diametralmente de um modelo de negócio com ênfase em capacidades e operando com uma estrutura orgânica, visando a fortalecer-se em seu segmento. Para a garantia da sustentabilidade ou aumento da competitividade, o desafio será sempre achar o equilíbrio certo com a ênfase correta para os objetivos desejados. Operacionalmente, o equilíbrio é alcançado por meio da alocação de recursos e do ajuste e modificação dos processos administrativos internos e transacionais de interface com o mercado. Conceitualmente, é alcançado pelo desenvolvimento de uma lógica de valor que permita à empresa criar valor para o mercado e dele capturar valor, pela resposta de aceitação deste às suas modificações. Em última análise, isso significa inovar em seu modelo de negócio.

Posto que a inovação se constitua em desafio inalienável da capacidade competitiva de qualquer empresa e que inovar em processos é tão ou mais sustentador quanto inovar em produtos, o desafio para os executivos é configurar seu negócio usando uma lógica de valor que possa ser assimilada e praticada pelos seus gerentes e suas estruturas operacionais. Numa empresa onde o conhecimento tácito e domínio tecnológico são essenciais para seus negócios quais seriam as características do modelo de negócio, em termos de lógica de valor e configuração usada na 
empresa selecionada? Nesta linha, o objetivo geral do estudo busca determinar como elementos inovadores configuram o modelo de negócio da empresa selecionada e que tem permitido exceder na qualidade de seus produtos, ampliar seu mercado nacional e expandir-se internacionalmente. Para tanto, são aqui descritos o modelo de negócio da Valduga, as características e a origem das inovações com influência em seu modelo de negócio e as implicações no conjunto das estratégias corporativas, competitivas e organizacionais da empresa.

Esta pesquisa justifica-se sua relevância ao estudar inovações no modelo de negócio da empresa objeto da pesquisa tem relevância científica e técnica principalmente por causa da natureza e nível de importância das relações entre as inovações e a eficiência do modelo de negócio. Sob o ponto de vista científico, este trabalho pode contribuir para o entendimento do modelo de negócio, que apresenta duas características marcantes: o suporte aos objetivos expansionistas da empresa e o suporte às peculiaridades estruturais próprias de uma empresa com usa aprendizagem empírica de tecnologias avançadas para fabricação de vinho. Outra possível contribuição deste trabalho, ainda no âmbito científico, envolve a descrição do modelo de negócio como arcabouço dos processos administrativos e de produção. Por ser baseado no conhecimento, esse conjunto pode induzir pesquisas a resultados que podem conter paradigmas desafiantes da teoria estabelecida. Neste conjunto considera-se o processo decisório e a formulação de estratégias como processos contingenciais ao modelo de negócio estabelecido ou perseguido. De outro lado, sob o ponto de vista técnico, a relevância deste trabalho reside em suas possíveis contribuições para o desenvolvimento de modelos de negócio que mais se aproximem ou se ajustem aos recursos e aos processos vigentes na empresa. Isso não somente ajuda a empresa adaptar seus processos de forma mais eficiente, mas também a desenvolver seu modelo de negócio (e respectivas estratégias) dentro dos recursos e capacidades que interessam mais diretamente aos seus objetivos empresariais.

\subsection{INOVAÇÃO - CONCEITOS E GENERALIDADES}

O conceito de inovação a partir de suas abordagens observada no pensamento de grandes estudiosos da inovação, como Skarzinski e Gibson (2008), Christensen e Raynor (2003), Kelly e Littman (2002, 2005), Davila, Epstein e Shelton (2005), é entendida como as alterações em processos, produtos e negócios que provocam renovação estratégica e aumentam os lucros empresariais. Abordada desta forma, a inovação apresenta fundamentalmente três dimensões essenciais: a dimensão do valor, a do custo e a da estratégia.

A dimensão valor se refere à perspectiva do cliente. Quando as alterações aumentam a elasticidade ao preço dos produtos, então a inovação provoca um aumento no valor do produto ou 
serviço, aos olhos do cliente (Christensen \& Raynor, 2003). O resultado é um óbvio aumento da preferência e demanda pelos produtos ou serviços vistos com maior valor pelos consumidores. No lado do negócio, a inovação com maior valor induz à renovação estratégica do negócio, aumentando a consolidação do posicionamento da empresa no mercado e à correspondente melhora de desempenho na sua lucratividade.

Na dimensão da inovação voltada aos custos esta representa os ganhos em produtividade e abaixamento relativo dos custos nos processos de manufatura. A inovação nesta perspectiva atua de duas formas: como instrumento provocador de abaixamento direto dos custos, mesmo que sem aumento da produtividade; ou pode provocar aumento de produtividade, sem necessariamente abaixar os custos diretos. De todas as dimensões da inovação esta pode ser percebida de maneira mais clara e direta pelo cliente. Por isso, simplistamente posto, essa dimensão é a mais efetiva forma de inovação.

Por fim, a inovação de caráter estratégico concentra-se no modelo de negócio. Nesta dimensão, a empresa remodela a concepção de seu negócio e alinha suas estratégias para ganhar ou aumentar suas vantagens competitivas (Skarzinski \& Gibson, 2008). Inovação estratégica contempla o desenvolvimento do ambiente cultural na organização para criar e sustentar ideias ao longo do processo de inovação com o intuito de diminuir riscos no espaço de novas oportunidades, maximizar o retorno das inovações, quer em aumento de vendas, quer em ampliação da aceitação da marca. E também ao estabelecimento dos mecanismos e sistemas que orientam a inovação como fundamento das competências essenciais da empresa.

De maneira geral, poder-se agrupar os tipos de inovação em três categorias, a partir de seu objeto, natureza e intensidade. Na categoria objeto pode-se ter inovação em produtos, processos serviços, modelo de negócio e mercado (Maital \& Seshadri, 2007). Neste caso, o tipo de inovação é bastante autoexplicativo e trata-se de inovação que envolve os elementos nos quais acontece a inovação ou onde ela pode ser observada.

A segunda categoria de inovação está ligada à sua natureza. Nesta categoria pode ser classificadaem inovações do tipo incremental, radical (Leifer, O`Connor \& Rice, 2002), disruptivo (Christensen, 2003), ou aberta (Chesbrough, 2003, 2007). São inovações que, respectivamente, melhoram gradativamente o desempenho ou a qualidade ou o design dos produtos; que quebram a trajetória dos processos tecnológicos tradicionais; que alteram os processos de negócio deslocandoos para segmentos de mercados menos exigentes ou para segmentos de baixo custo fazendo com que novas empresas, sem a mesma capacidade de investimento em inovações, assumam a frente ou co-liderem seus setores econômicos (Christensen \& Raynor, 2003). 
A terceira categoria de inovação são as do tipo radical é definida por Leifer et al. (2002, p.18) como um "produto, processo ou serviço que apresenta características de desempenho sem precedentes ou características já conhecidas que promovam melhoras significativas de desempenho ou custo e transformem os mercados existentes ou criem novos mercados”. Uma das diferenças importantes entre a inovação radical e a disruptiva é que a última está normalmente associada ao modelo de negócio e seus processos, enquanto que a primeira está associada a soluções tecnológicas capacitadoras de novas aplicações de produtos e serviços.

\subsection{ESTRATÉGIAS DE INOVAÇÃO}

A capacidade competitiva de um negócio, que tem por base o domínio tecnológico e inovação, é hoje "necessária mais do que nunca" (Prahalad \& Ramaswamy, 2003, p. 12). Não é apenas uma questão de prescrições tradicionais, como a redução de custo, melhor administração, controle mais restrito, melhor organização, reengenharia ou terceirização, mas é essencialmente uma questão de criar valor de maneiras percebidas e que sensibilizem o consumidor. Esse é o caminho da inovação, que assim concebida, afeta o negócio em todas as suas formas e atividades e o único caminho para as empresas conseguirem um crescimento sustentável.

Uma rápida análise da evolução das estratégias de inovação mostra que nos últimos 80 anos, a inovação tem sido estudada em ondas de abordagem. A iniciar-se no pensamento da "destruição criativa" de Schumpeter (1961), a estratégia corporativa considerava a inovação como um instrumento administrativo capaz de provocar mudanças na indústria. Para Schumpeter (1961), a destruição criadora acontece quando a morte de uma indústria ou uma atividade industrial cede lugar àoutra, com maior potencial econômico (por exemplo, a indústria da carruagem cedeu lugar à indústria do carro; ou o mainframe cedeu lugar ao computador pessoal). A destruição criativa representa os passos evolutivos da economia de livre mercado.

Por volta da década de 1980, a estratégia da inovação na indústria considera as descontinuidades tecnológicas como mecanismo dominante do processo de inovação, como alavanca impulsionadora da evolução industrial. Tushman e Anderson (1986) definem estas descontinuidades como a competência de uma inovação sobre uma tecnologia dominante em aperfeiçoá-la ou destruí-la e substituí-la. Descontinuidade do tipo competência-destruidora torna a tecnologia substituída totalmente obsoleta (por exemplo, a tecnologia de válvulas de tubo ficou obsoleta com a entrada da tecnologia de circuito integrado). Já a descontinuidade do tipo competência-criadora aperfeiçoa a tecnologia com base no acúmulo de know-how sobre aquela 
tecnologia (por exemplo, a tecnologia de turbinas evoluiu como know-how acumulado da precedente tecnologia de turbo-hélices). É durante esse período que se começa a fazer a distinção da inovação radical, em geral associada ao conceito de descontinuidade do tipo competênciadestruidora (Anderson \& Tushman, 1990).

Na década de 1990, Christensen (2003) introduz o conceito de tecnologias disruptivas como uma forma de usar a inovação para quebrar as regras de dominância dos líderes de um setor. Ainda na década de 1990 que são introduzidos os conceitos de exploitation e exploration (exploração interna e externa) de ativos tecnológicos como forma de construir a resiliência organizacional (March \& Puhan, 2008).

Mais recentemente, nesta década, os estudos de Leifer et al. (2002) mostram as novas formas de uso da estratégia de inovação, agora de forma radical, como alternativa para contra-atacar o impasse da estratégia incremental, que poderia levar as empresas tradicionais a serem surpreendidas por inovações disruptivas no formato de seus negócios. Christensen e Raynor (2003) contrapõem às abordagens incremental e radical de Leifer et al. (2002), o conceito de inovações sustentadoras, mais ligadas ao conceito de domínio tecnológico. Inovação disruptiva, para esses autores, está mais voltada para as inovações nos processos de negócio. Finalmente, Chesbrough (2003; 2007) observa que há um movimento claro de um novo formato na estratégia de inovação, em direção à busca de fontes cognitivas externas, que ele chamou de Inovação Aberta. Esses movimentos e a forma de acessar e desenvolver a inovação são de fato, estratégias empresariais de inovação.

\subsection{INOVAÇÃO E MODELO DE NEGÓCIO}

Quanto melhor as empresas constroem ou concebem seus negócios, defende Hamel (2000), maiores são as chances de vencer e prosperar em seu ambiente de operação. Antigos negócios, pensados dentro dos padrões estruturados da era industrial da produção em massa, precisam se reconceber, para a nova era da produção mediada pela inovação (Quinn et al.,1996). Desde que os negócios passaram a centralizar suas funções nos consumidores, a inovação passou a ser elemento crítico de eficiência e flexibilidade. Novas formas de organizar os negócios, em especial em rede, estão sendo experimentadas na tentativa de responder melhor ao domínio da inovação.

Para Hamel (2000) a era da mudança gradual acabou. O domínio competitivo das multinacionais não possui mais a estabilidade que tinha no passado. No entanto, há necessidade de inovação nos conceitos de negócio de forma radical, criando novo valor para os clientes, duras 
surpresas para os competidores e mais riqueza para os investidores.

Para reconceber negócios inovadores Hamel (2000) aponta quatro componentes básicos: (a) A Estratégia Central - como a empresa escolheu competir, o objetivo da sua estratégia, onde a empresa compete e quão diferentemente a empresa compete; (b) Os Recursos Estratégicos - qual base de recursos é utilizada - da empresa ou terceirizada. Incluem competências básicas, patrimônios estratégicos e processos essenciais; (c) A Interface com o Cliente - canais usados para atingir os clientes, a informação fornecida a eles, a maneira de administrar a dinâmica da relação e a forma de se precificar produtos e serviços; e (d) A Rede de valor - fornecedores parceiros e coalisões que envolvem a empresa complementando e expandindo os recursos da mesma. Os componentes da reconcepção do negócio apontados por Hamel(2000) parecem funcionar bem dentro dos princípios e requisitos de negócios horizontais, apontados por Hagel III (2003).

\subsubsection{CONECTIVIDADE INTERORGANIZACIONAL E O MODELO DE NEGÓCIOS}

Hagel III (2003) propõe uma evolução no formato dos negócios, com base na interconectividade das empresas. As premissas de Bovet e Martha (2001) acerca do modelo de negócio em redes de valor, na perspectiva das cadeias de suprimento e na formação de rede na "nova” concepção de negócio de Hamel (2000), evoluem em Hagel III (2003) para sustentarem os requisitos da horizontalidade dos negócios, concebidos por meio dos serviços Web. Estes são serviços de conectividade entre computadores de qualquer idade, plataforma e origem construtora (servidores, estações, celulares, guizmos, laptops, agendas eletrônicas, palmtops e outros), com base em um novo padrão de interconexão em rede.

Hagel III (2003) ressalta que para chegar a orquestrar seu negócio horizontalizado em rede, as empresas passam por três estágios de maturação em seu negócio (Figura1).

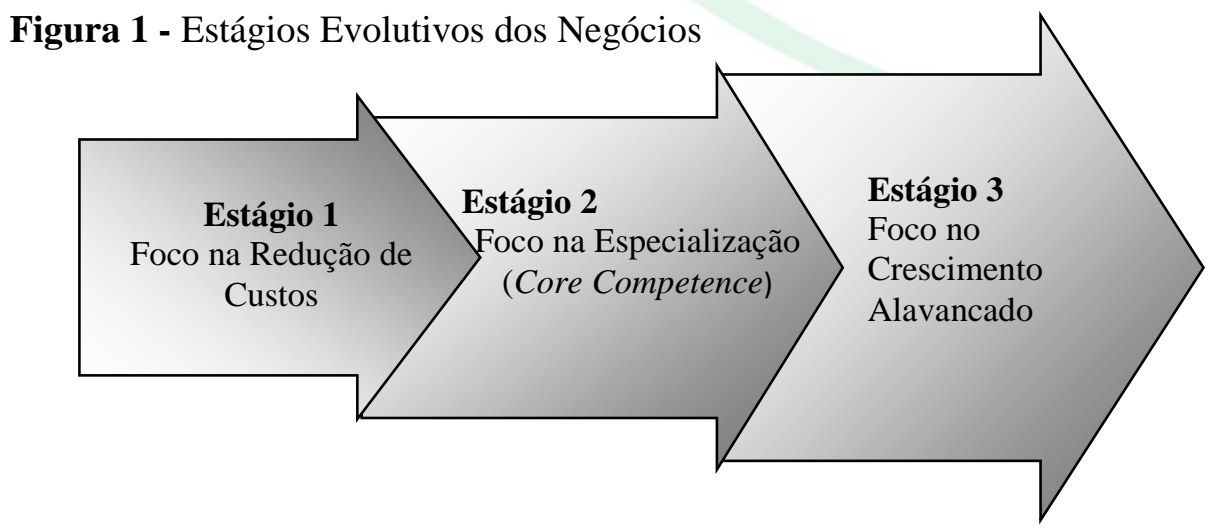

Fonte: Adaptado de HAGEL III (2003). 
No primeiro estágio, as empresas focam a lucratividade no curto prazo. O esforço de suas estruturas gerenciais é com o ajuste e eficiência dos processos produtivos, com sua integração no nível da empresa e com empresas diretamente ligadas à consecução de seu negócio. No segundo estágio, as empresas buscam a criação de especialidades em até três áreas: relações com os clientes, infraestrutura de TI e comercialização e inovação. Ao imaginarem seus negócios, as empresas passam a criar especializações em uma destas dimensões. Finalmente, no terceiro estágio, as empresas se voltam para o crescimento. Este crescimento, no entanto, estará condicionado ao crescimento da rede de organizações ligada a ela. Desta forma, a empresa precisa oferecer vantagens econômicas a seus parceiros para poder fazê-los crescer e em consequência acarretar o crescimento mútuo.

Para Hagel III (2003) o conceito de negócio significa trabalhar em rede, apostar no senso colaborativo interorganizacional, e na formação de clusters. As empresas-referência na rede precisam construir a rede e liderar a iniciativa da colaboração e confiança entre as componentes da rede. Segundo Hagel III (2003), isto se dá de três formas distintas: (a)

Agregação; (b) Orquestração; e (c) Modelação. A Figura 2 apresenta as plataformas de crescimento e os respectivos papéis das organizações.

Figura 2 - Plataformas de Crescimento

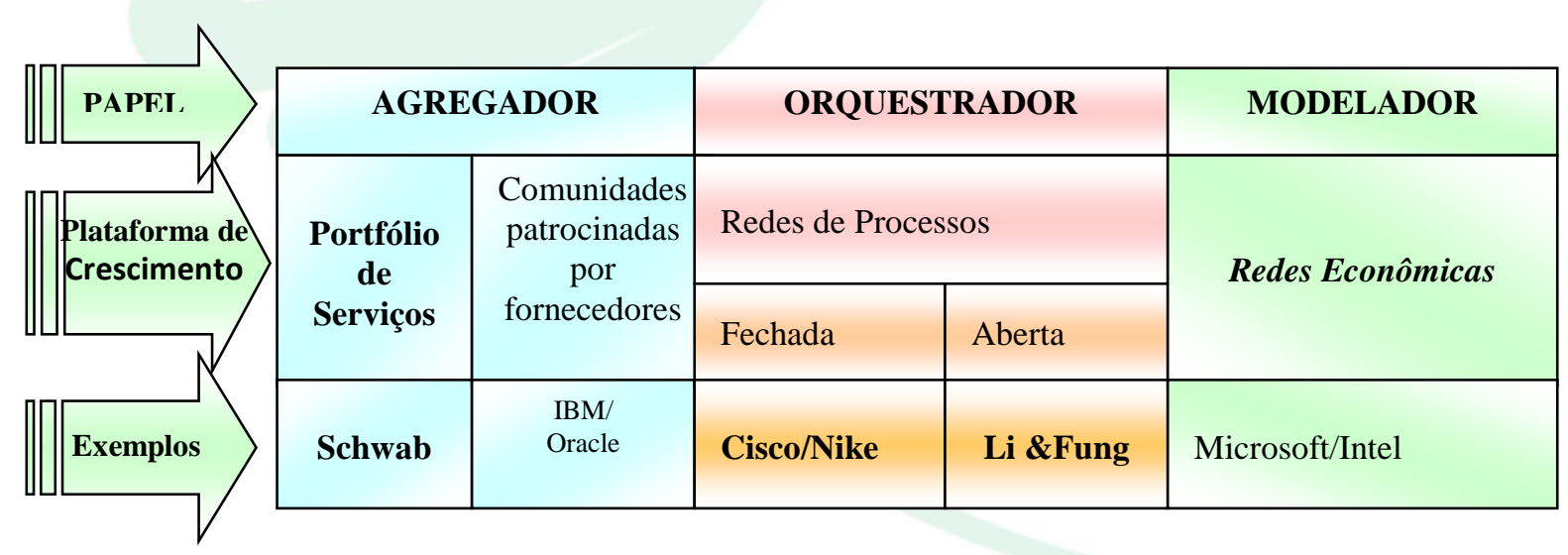

Fonte: HAGEL III (2003, p. 206).

De acordo com a Figura 2, o agregador é uma organização que, por meio de sua rede serviços oferece seletivamente um vasto conjunto de alternativas e recursos de serviços especializados de terceiros, para ajudar seus clientes a tomarem suas decisões. Nesta plataforma, Hagel III (2003) aponta a Schwab, a IBM e a Oracle como exemplos de organizações com papel de agregador na gestão da rede. 
No entanto, o orquestrador administra a nebulosa de organizações que compõem sua rede, de duas formas: fechada e aberta. Uma orquestradora fechada escolhe suas parceiras e indica sob que normas e com que material as parceiras devem executar os serviços ou produzir os bens. $\mathrm{Na}$ orquestradora aberta é, no fundo, uma grande intermediadora, que estabelece as regras, mas não interfere na produção dos bens, já que suas parceiras são as especialistas na produção daqueles bens.

As modeladoras são organizações capazes de determinar plataformas tecnológicas padrões para seus setores, por que dominam a tecnologia ou os padrões de operação, que fundamentam a geração dos produtos do setor. Microsoft e Intel são os exemplos mais clássicos de organizações modeladoras. A primeira concentrou-se no sistema operacional (DOS) e a segunda, na produção de microprocessadores de alto desempenho. Ambas construíram uma ampla rede de organizações parceiras que desenvolvem os aplicativos e o sharedwarede usuários (aplicativos compartilhados), respectivamente, dentro dos padrões de operação ditados por elas.

\subsubsection{MODELO DE NEGÓCIO DAS REDES DE VALOR}

Pouco antes de Hagel III (2003), Bovet e Martha (2001) estudaram profundamente o modelo de negócio a partir da questão das cadeias de suprimento. Estes defendem que hoje o antigo conceito de cadeia de suprimento deixa de existir para ser substituído pelo conceito de Rede de valor. Uma rede de valor é um sistema rápido, flexível, alinhado e orientado pelas escolhas dos clientes. Bovet e Martha (2001) propõem que o modelo de negócio de uma empresa competitiva tem como base cinco elementos de modo a formar uma Rede de valor. Qualquer negócio precisa apresentar uma Proposta de valor. Essa proposta envolve a declaração dos serviços e seus adicionais distintivos de outros negócios similares e concorrentes. Além disso, explicita as soluções de conveniência e as personalizações incorporadas que beneficiarão diretamente o cliente.

Um segundo elemento refere-se à Abrangência do negócio, ou do que se está oferecendo. A abrangência envolve o mapa de escolhas que a clientela terá nos processos e produtos do negócio. Enfatiza como o negócio cria valor para o cliente e dele captura valor para a empresa. E finalmente, define os processos e as terceirizações predefinidas no negócio.

O terceiro elemento refere-se à Obtenção de lucro, isto é, quais são as fontes de lucratividade neste modelo e como pretende alcançar as metas de retorno sobre o capital investido. O quarto elemento envolve o Controle Estratégico, isto é, como a empresa protege sua fonte de lucro por meio do estabelecimento de vantagens competitivas sustentáveis. O controle estratégico considera a marca, a 
política de preços, as relações institucionais (com clientes e fornecedores) e a comunicação da inovação. Finalmente, o quinto elemento, diz respeito à Execução, queé estabelecer a operação integrada das capacidades humanas, como empreendedorismo corporativo, cultura de breakthrough, liderança, metas organizacionais e investimento em novas habilidades.

\section{MÉTODO DE PESQUISA}

Esta pesquisa tem por objetivo buscar identificar o perfil e as características do modelo de negócio da Valduga, por meio de um estudo de caso. Situações de pesquisa que levem à busca do “como" e "porque", segundo Yin (2005), caracteriza a adequação de uso do método de estudo de caso. Nesta perspectiva, se busca descrever e apontar como a Casa Valduga estabeleceu a lógica de valor para configurar seu negócio, de forma a atingir seus objetivos.

A escolha do objeto de estudo desta pesquisa justifica-se uma vez que, desde meados do século passado, a Casa Valduga vem liderando o comportamento entre os membros de sua comunidade vinicultora da Serra Gaúcha. Esta comunidade se constitui, em sua maioria, de famílias descendes de imigrantes italianos, que em sua origem, na Itália, eram pobres e com nível educacional primário, vivendo em condições de miséria. Esses imigrantes vieram para o Brasil com o objetivo de sobreviver. Aqui, viviam da terra e acessavam aos bens e produtos por meio de simples escambo. O espírito inovador da Casa Valduga, no entanto, começa a aparecer quando o pai da atual geração de gestores desta empresa começa a usar a uva como moeda de troca para a produção de suco de uva, por uma empresa regional de produção de sucos, nos idos de 1950. Assim, inicia-se o negócio da Casa Valduga. Para analisar o caso, na abordagem dos fatores de inovação que sustentam os negócios da Casa Valduga, a extrapolação de conteúdos teóricos, a partir de um estudo de caso, na aferição de Pozzebon e Freitas (1998), e Eisenhardt (1989) pode ser realizada, dependendo da técnica utilizada na coleta, análise e interpretação dos dados. Para tanto, adotou-se neste estudo de caso o modelo de pesquisa adaptado de Gordon (2001), conforme a Figura 3. 
Figura 3 - Protocolo para estudo de caso

ANÁLISE CONTEXTUAL

\section{DESCRIÇÃO}

\begin{tabular}{|c|}
\hline COLETA DE DADOS \\
[Observação, Entrevista, \\
Documentação, Questionário] \\
\hline
\end{tabular}

PRESCRIÇÃO

\section{SOLUÇÕES - CONCLUSÕES}

[Identificação e proposta de soluções ou formas de alterar a situação]
ANÁLISE PROCESSUAL

\section{DIAGNOSE}

\section{PROBLEMAS OU CAUSAS}

DE SUCESSO-INSUCESSO

[Identificação do(s) problema(s) ou das causas de sucesso que levaram à situação atual]

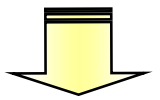

\section{INTERPRETAÇÃO}

\section{CAUSAS X EFEITOS}

[Teorias e conceitos da Literatura Especializada para entendimento das relações entre causas e efeitos]

Fonte: Adaptado de Gordon (2001).

A coleta de dados assim foi realizada por meio de observação não participante, com a permissão e aquiescência dos gestores da empresa. Esta fase de coleta de dados, apoiado em um bloco de notas, permitiu um primeiro contato com o ambiente em estudo. As entrevistas pessoais aconteceram em diferentes tempos, por razões de agendamento, sendo os sujeitos sociais correspondentes aos três gerentes considerados como elementos-chave e com funções estratégicas na empresa: o Diretor Geral, Sr. Juarês Valduga; o Diretor de Marketing, Sr. Fabiano Olbriech; e o Diretor da Domno Brasil, Sr. Jones Valduga. A história da família aponta maior foco no Sr. Juarês; o posicionamento do negócio, suas bases inovadoras e sua interface com o mercado no Sr. Olbriech; e a estrutura, papel da qualidade e controles estratégicos com maior foco no Sr. Jones. Desta forma, esta amostra intencional emergiu do próprio ambiente de pesquisa. As entrevistas foram gravadas e depois transcritas para posterior análise. A análise dos dados levantados foi realizada por meio da técnica de análise de conteúdo, tendo em Bardin (1977) o seu delineamento. 
Leonel Cezar Rodrigues, Amelia Silveira, Carlos Mamori Kono \& Fernando Cesar Lenzi

\section{ANÁLISE E INTERPRETAÇÃO DOS RESULTADOS}

O estudo do caso evidencia que a família Valduga veio para o Brasil em 1875, fugindo de um período pré-revolucionário francês, em que miséria e fome grassavam na Europa, e em especial na Itália. No Brasil, os imigrantes italianos não encontraram soluções melhores de infra-estrutura do que eles tinham em sua terra natal, mas pelo menos havia terra para ser cultivada. As primeiras culturas foram as de subsistência, tais como milho, legumes, batata, abobrinhas, etc., e pecuária de corte (porco, gado, galinhas). Com terra e clima favorável, no entanto, as mudas de uvas, trazidas como pequenos ramos no bolso do sênior Valduga brotaram, foram reproduzidas e produziram uvas.

Inicialmente, as uvas que eram de qualidade inferior para a produção de vinhos (eram uvas Isabel, boas para consumo de mesa e para a produção de sucos) eram consumidas totalmente pela família. Foi somente por volta da década de 1950 que a uva foi transformada em produto de valor econômico pela família. O aumento e o cuidado com a produção permitiu que os Valdugas pudessem vender sua uva, in natura, para as grandes casas locais, que produziam suco de uva. Começava assim, o negócio da família Valduga. Apesar de trabalhar com um tipo de uva não muito apropriada para a produção de vinho, a família iniciou a produção de vinho caseiro, tipo de garrafão, para consumo próprio, e eventual escambo. Produzir e gerar vinho não se constituía, nesta fase, o centro de negócios.

Produzir uva para vendê-la como matéria prima para a produção de sucos foi uma forma de negócios que perdurou em, pelo menos, uma geração na família. No início da década de 1970, no entanto, os negócios da Casa Valduga entraram numa nova era. Após a morte do pai, os quatro filhos reuniram-se, compraram um negócio independente para um deles e os outros três juntaram-se para formar o que veio a ser a Casa Valduga de hoje. O Sr. Juarês Valduga assumiu a direção geral dos negócios, enquanto João assumia a parte das atividades enológicas - plantio, sepas, varietais - e Erielson, a parte da produção de todo o portfólio de produtos da Casa Valduga.

A Casa mudou seu modelo de negócio, deixando de produzir sucos e passando a dedicar-se à produção de vinhos e de espumantes de alta qualidade. A primeira providência foi alterar o formato de cultivo da uva, do tradicional modelo em parreirais, para o modelo em espaldeiras. Desta forma, a uva poderia receber maior insolação, aumentando seu teor de açúcares, permitindo então o desenvolvimento de vinhos mais finos. A segunda providência foi a diversificação do plantio para varietais mais nobres, introduzindo uvas do tipo Merlot, Cabernet-Sauvignon, Chardonnay, Sauvignon, e outras. A terceira providência foi expandir os espaços de plantio. Para 
isso a Casa começou a adquirir várias áreas adjacentes nas redondezas e em outras cidades, como Encruzilhada do Sul, mas sempre no Rio Grande do Sul.

Hoje os negócios da família são administrados pela HoldingValduga, que controla quatro negócios independentes: (a) a Casa Valduga, que vem operando como o centro dos negócios, produzindo e comercializando vinhos e espumantes finos, desde 1973; (b) a Casa de Madeira, adquirida em 1990, que produz geléias finas à base de uvas de casta, como a Cabernet-Sauvignong, a Malbec, a Merlot, produz sucos de uva e possui um restaurante gourmet anexo, para experimentação de receitas da Casa; (c) a Vila Valduga, estabelecida em 2005, que administra a pousada da Casa e cuida de eventos turísticos relacionados como a festa da colheita, o tour degustação e o restaurante da Casa Valduga; e (d) a Domno Brasil, estabelecida somente em 2008, dedicada a fazer o que a Casa Valduga, por definição, não pode fazer: importar vinhos finos especialmente de países sul americanos e comercializá-los no mercado brasileiro. A Domno também faz espumantes, mas pelo método charmat, com uvas compradas de pequenos produtores locais e vinificadas, provisoriamente, nos tanques da Casa Valduga.

Nesta última década, uma nova geração de Valdugas começa a ocupar espaços nos negócios da família. A Domno Brasil, por exemplo, é administrada por Jones Valduga, filho de João Valduga. Começam também a fazer a Casa experimentar o ambiente internacional, com Eduardo, filho de Juarês Valduga iniciando a experiência de produzir vinhos terroir em países da América do Sul (Argentina e Chile) e Europa (Portugal e, recentemente, Itália), por arrendamento de safras e dos serviços de casas locais. Os vinhos assim produzidos são comercializados sob a marca MUNDVS, da própria Valduga, para o mercado brasileiro. A Valduga exporta hoje para 13 países no mundo, incluindo Estados Unidos e Canadá, Europa, Leste Europeu e Ásia.

\subsection{AS INOVAÇÕES NA CASA VALDUGA}

A Valduga entra na segunda década deste século com um invejável portfólio de vinhos, de grande variedade e fino paladar. No topo de seus vinhos está o STORIA, um Merlot doc (denominação de origem controlada) produzido somente em safras excepcionais. Depois vêm o VILLA LOBOS, um Cabernet-Savignon selecionado e a linha de vinhos IDENTIDADE, brancos e tintos. Abaixo dos Identidade vem a Linha GRAN RESERVA Valduga e a linha de vinhos PREMIUM. No mesmo nível, porém, com uma história de origem e produção distinta situam-se os vinhos da linha MUNDVS. Abaixo desse conjunto vêm os vinhos compostos de dois varietais: os DUETOS. Por fim, vem a linha dos vinhos mais acessíveis e que inclui espumantes: a linha 
AMANTE e a linha ARTE. Fechando o portfólio vêm os vinhos de marca NATURELLE, a linha mais barata de vinhos da Casa.

Em termos de espumantes, a Valduga produz, genericamente, três categorias, todos pelo método tradicional champenoise: o Maria Valduga, o mais nobre e recém-lançado; o espumante Valduga 130, premiado em concurso internacional, em Paris, e os espumantes PREMIUM e ARTE. São, no total, cerca de 30 tipos de vinhos tintos e brancos, distribuídos ao longo de suas sete marcas e 13 tipos de espumantes, desde o moscatel até os extra brut.

Se o modelo de negócios de Bovet e Martha (2001) for utilizado para amparar a interpretação do modelo de negócio da Valduga, pode-se analisar o que aqui foi descrito da seguinte forma:

- Proposta de valor - A Casa Valduga tem perfeita consciência da qualidade e do papel da qualidade em seus produtos. Qualidade em seus vinhos e espumantes é o que a Casa tem de maior valor, para oferecer para seus clientes. Preservar a qualidade e associá-la à sua marca é a forma como tudo é pensado e executado, desde as inovações que não aparecem para os clientes, (plantio, maceração, vinificação, filtragem, etc), até sua política de comercialização (não disponibilidade em supermercados) e precificação. Como coloca o Sr. Juarês: "qualidade para nós é tudo. Não fazemos nada que vai diminuir a qualidade de nossos vinhos, nenhum investimento, nenhuma modificação... Isso não é bom para a Valduga, para nossa marca...".

- Abrangência - O negócio de vinhos é amplo e variado, em especial no Brasil. Os segmentos consumidores são, da mesma forma, amplamente distintos e em geral preocupados mais com preços do que com qualidade. Para não dissociar o nome Valduga do sentido qualidade, a Casa resolveu manter-se exclusivamente dentro dos limites que lhe permitem total controle sobre o que oferece. Seu mapa de escolhas é amplo, como apontado anteriormente, envolvem mais de .... produtos, caracterizados ao longo de 13 marcas. Apesar de poder comercializar outros vinhos, prefere limitar-se ao que tem pleno controle, não permitindo-se terceirizar, para garantir valor pela qualidade de seus produtos. Oportunidades de comercialização de bons produtos são realizadas por meio da Domno Brasil: "O nosso negócio e o da Valduga, são diferentes. Lá temos um controle forte sobre o que fazemos. Não podemos (nem queremos) vacilar na qualidade. Aqui podemos 
experimentar outros caminhos. Se erramos aqui, a Valduga não sofre...”, observa Jones, o Diretor da Domno Brasil.

- Fonte de lucratividade - A lucratividade do negócio da Casa está claramente assentada sobre sua proposta de valor e o segmento de mercado em que atua. Como produz vinho de alta qualidade, acima da média de bons vinhos importados, principalmente da América do Sul, a Casa aplica uma política de precificação suportável pelo segmento consumidor que interessa às classes A e B. Essa política de preços lhe garante a lucratividade suficiente para equilibrar o capital imobilizado durante o tempo de elaboração dos vinhos e espumantes, segmentar seu mercado de interesse e garantir a distinção de suas marcas.

- Controle Estratégico - Vários são os fatores que determinam o controle estratégico da Casa, isto é, as áreas de vantagens competitivas sustentáveis de seu negócio. Pode-se, no entanto, apontar três áreas como as mais críticas. Primeiro é ter terra com clima favorável para adaptação das espécies de uvas, plantados de forma a receber a maior insolação possível (reconversão dos vinhedos em espaldeiras). Segundo, domínio absoluto dos processos de vinificação, desde a colheita, maceração, fermentação, filtragem, maturação e engarrafamento. Terceiro, o uso de equipamentos e insumos de alto desempenho nos processos de produção. $\mathrm{Na}$ Valduga, isso transparece especialmente no uso de cepas de fermentação sempre originais, uso de tanques de fermentação de aço inox e uso de prensa isobarométrica - mais comumente chamados de filtro-prensa - para o processo de filtragem dos vinhos e espumantes, garantindo a qualidade dos produtos.

- Execução - na concepção de Bovet e Martha (2001) a execução de um modelo ideal de negócio deve primar por uma liderança visionária, uma cultura de breakthrough, uma equipe empreendedora, possuir metas simples e claras e ter atenção ao desenvolvimento de novas habilidades. Esses são requisitos que parecem estar plenamente satisfeitos no modelo de negócio da Casa. A observação do Sr. Olbriech, Diretor de Marketing, a respeito da gestão do Sr. Juarês, mostra a presença da liderança visionária e da cultura de breakthrough: “...a gente sempre tem que estar puxando ele para a realidade. Ele empurra muito o negócio com suas idéias, aquisições e faro para mostrar tendências...mas, às vezes, a gente até precisa ser mostrar mais conservador para ficar fiel à proposta [do negócio] da Valduga.". A presença de diretores e de membros da Casa nos restaurantes (Casa Valduga e Casa de 
Madeira), por exemplo, tem o objetivo de obter feedback sobre os pratos, qualidade da comida, atendimento, harmonização etc. De outro lado, os membros da Casa são constantemente desafiados a contribuírem com ideias novas, que são cuidadosamente analisadas pelos diretores e alta administração. Com base nesta constante atenção à execução do negócio, à adoção de novas ideias, novos avanços tecnológicos, são determinados os objetivos e as metas da empresa, de forma precisa, para que todos entendam o que se passa em realidade e para que sejam feitos os investimentos no desenvolvimento de novas habilidades. Por exemplo, a produção do MUNDVS, por meio do arrendamento de safras inteiras de terroir fora do Brasil, veio desta constante preocupação com ideias novas e espírito empreendedor da equipe da Valduga.

\subsection{CARACTERÍSTICAS E NATUREZA DAS INOVAÇÕES NA CASA VALDUGA}

As características das inovações presentes na empesa analisada possuem duas origens distintas, mas objetivam um fim único: a preservação da forma e da qualidade do negócio da Casa. De um lado, as inovações que sustentam o negócio orientam-se para a base tecnológica da empresa. De outro, o modelo de negócio alinha-se a processos que garantem as premissas que orientam o modelo.

As inovações tecnológicas introduzidas nos últimos 40 anos foram o foco em uvas viníferas; a reconversão dos vinhedos; a substituição dos tanques de fermentação de madeira por tanques de aço inoxidável; e a introdução da prensa isobarométrica, com maior capacidade de volume de vinho filtrado e maior capacidade de retenção de partículas de tamanho menor.

O uso de uvas viníferas, como a cabernet-sauvignon, a merlot, a chardonnay, em substituição às uvas Isabel, mais próprias para consumo direto da fruta e para a produção de sucos, abriu o caminho para a possibilidade de produção de vinhos verdadeiros. A reconversão de vinhedos no formato tradicional (em parreiras) para vinhedos em espaldeiras foi um marco histórico determinante para permitir a Casa entrar na produção de vinhos finos. A disposição dos vinhedos em espaldeiras permite maior insolação, dando à uva maior carga de açúcares, essencial para a boa fermentação. A substituição dos tanques de madeira por aço inox elimina os problemas de contaminação, durante o processo de fermentação, garantindo a otimização do processo e o desenvolvimento dos subprodutos certos, em termos de cor, acidez, sabor e odor. Por fim, a introdução de prensa isobarométrica é uma garantia da perfeita filtração do vinho, a parada 
completa da fermentação no ponto exato, conferindo ao produto final a textura, composição, sabor e odores característicos e desejáveis.

No que se refere ao modelo de negócios é importante frisar que o esforço da empresa para garantir a qualidade de seus produtos, associando-a à marca, é amparado com processos equivalentes. Por exemplo, a Valduga não vende seus produtos em supermercados, por causada negligência de manuseio e necessidade de exposição, que não observam as regras básicas de manuseio do vinho. Em supermercados, o vinho é mudado constantemente de lugar, a garrafa é, na maioria das vezes, exposta de pé e em lugares bem iluminados. Todas essas práticas são exatamente contrárias àquelas necessárias para preservar a qualidade do vinho. Os vinhos Valduga são vendidos somente em lojas especializadas em revenda de vinhos ou diretamente para restaurantes.

\subsection{IMPLICAÇÕES NAS ESTRATÉGIAS CORPORATIVAS, COMPETITIVAS E ORGANIZACIONAIS DA EMPRESA}

As implicações decorrentes da constante atenção da Casa à qualidade de seus produtos e o consequente modelo de negócio, para as estratégias corporativas, competitivas e organizacionais são pontuais, mas ao mesmo tempo críticas para o bom andamento do negócio. Com um modelo de negócio muito bem definido em termos de suas plataformas e de sua premissa norteadora (qualidade dos produtos de seu portfólio), as implicações voltam-se fundamentalmente para a combinação de seus recursos e capacidades, visando dar à empresa uma posição de liderança em seu segmento de mercado. Daí, as implicações para as estratégias e estruturas internas da empresa podem ser resumidas em:

- Estratégia corporativa - em termos de estratégia corporativa, o foco mais crítico foi o domínio tecnológico. Tudo se define a partir da base tecnológica utilizada pela empresa. $\mathrm{Na}$ Valduga a tecnologia está centrada na combinação dos recursos materiais, especialmente equipamentos e insumos para fermentação de qualidade superior, com os processos de vinificação (uvas cultivadas e selecionadas dentro das mais modernas técnicas de plantio, coleta, maceração, fermentação e vintage), que possa garantir a seus produtos a qualidade que a empresa comunica ao mercado. 
Leonel Cezar Rodrigues, Amelia Silveira, Carlos Mamori Kono \& Fernando Cesar Lenzi

- Estratégia Organizacional - a estratégia organizacional na Casa, isto é, o perfil da estrutura organizacional, as linhas de poder, a divisionalização das tarefas, as linhas de comunicação e a distribuição de poder nas várias camadas hierárquicas, é simples e direta no sentido de objetivar o alcance das metas de negócio. As linhas hierárquicas são poucas (4 linhas apenas), a equipe enxuta e as linhas de comunicação favorecem a estrutura orgânica da empresa, dando-lhe dinamicidade, rapidez decisória e eficiência administrativa. $\mathrm{O}$ processo decisório é centralizado apenas para as decisões de natureza estratégica ou institucional.

- Estratégia Competitiva - nitidamente a estratégia competitiva da Valduga é de liderança em seu setor. Para isso, fundamenta seu esforço de penetração mercadológica em se segmento na demonstração de seu domínio tecnológico. A lógica de valor associada à configuração de seu negócio - premissas da qualidade - é criteriosa e intransigentemente comunicada e exigida de seus diretores. Essa lógica, tornada realidade, transforma-se em atributo de valor em seus produtos e é, paralelamente, utilizada como alavanca para criar intangíveis como feeling, status e diferenciação, associados à sua marca. Isso torna os atributos de acesso, que normalmente guiam a política de precificação, uma consequência natural de sua conduta estratégica.

Pode-se, portanto, perceber que as estratégias corporativas, organizacionais e competitivas são coerentes e suplementares. Coerentes porque estão ligadas e são positivas, não contraditórias. São suplementares por que são somatórias umas às outras, isto é, a premissa da qualidade é suportada pela alocação de recursos em plantio adequado, em insumos e equipamentos que podem garantir a eficiência dos processos e alcançar a qualidade desejada, tudo suportado pelas estratégias corporativa e organizacional. A organicidade da estrutura da empresa soma-se ao alinhamento de funções e infraestrutura interna e a interface com o mercado mostra uma empresa que não descuida em nenhum momento de seus fundamentos (garantia de mercado pela qualidade e eficiência produtiva). 
Inovação e Modelo de Negócio - Um Estudo de Caso no Setor Vitivinicultor

\section{CONSIDERAÇÕES FINAIS}

A pesquisa objetivou determinar quais as inovações e sua natureza, que configuram o modelo de negócio da Casa Valduga responsável pelo seu desempenho e bom posicionamento no mercado brasileiro de vinhos e espumante finos. Norteada pela pergunta de pesquisa o propósito deste estudo de caso identificou e descreveu o modelo de negócios da Casa Valduga, as características, a natureza e as inovações em seu modelo e as implicações para as estratégias corporativas, competitivas e organizacionais. Com base no estudo observacional, nas entrevistas e no acesso às informações oficiais da empresa, pode-se concluir que:

- Em relação ao seu modelo de negócio, este é construído sobre uma sólida filosofia de qualidade. Todos os requisitos da qualidade são condições essenciais para alocação de recursos, desenvolvimento de capacidades e competências na empresa. A qualidade é o fundamento para a proposta de valor, para a abrangência, para as fontes de lucratividade, para a área de controle estratégico e para a estratégia de execução das atividades do negócio.

- As inovações de origem tecnológica e as inovações de origem transacional, isto é, relativas ao modelo de negócio da Casa, de um lado, consolidam a base de domínio tecnológico, a infraestrutura e os processos que garantem a qualidade técnica dos produtos da Casa. De outro, estendem essa garantia ao ambiente de mercado, por meio de adequados processos transacionais (vendas somente por meio de lojas especializadas, não supermercados), de disponibilidade e acondicionamento adequados à garantia do nível de qualidade determinado.

- A implicação das premissas do modelo de negócio da Valduga para as estratégias corporativas organizacionais e competitivas tem sua origem nas estratégias corporativas, não nas competitivas. Em outras palavras, a Valduga preocupa-se primordialmente com seu alinhamento interno (tecnologia, processos, recursos e capacidades) para garantir a qualidade de seus produtos e assim competir. Seu posicionamento no mercado é resultante de atributos de valor intangíveis (status, diferenciação e feeling), cuidadosa e incansavelmente construídos ao longo dos anos, com base na percepção da qualidade de seus produtos pelo seu mercado alvo. 
Fica claro, dessa forma, que a Valduga foca com clareza três atributos de valor de fundamento (qualidade, tecnologia e inovação) para desenvolver os atributos de valor intangíveis associados à sua marca (status, diferenciação e feeling). Entenda-se que a tecnologia está associada à combinação de insumos de qualidade superior, de equipamentos de produção de última geração e de processos próprio de absoluto domínio. O formato de distribuição e disponibilização de seus produtos ao mercado, além de garantir a qualidade desejada, atribui aos produtos da Valduga características singulares de distinção, percebidas e valorizadas pelo seu segmento de mercado.

Finalizando sugere-se que pesquisas complementares a que aqui se apresenta explorem as estratégias de internacionalização da Casa, com base em sua percepção singular de criar experiências internacionais, por meio dos arrendamentos de safras em outros países, dentre tantos outros aspectos que emergiram ao longo da descrição deste estudo de caso, para amparar futuras pesquisas.

\section{REFERÊNCIAS}

Bardin, L. (1997). Análise de conteúdo. Lisboa: Edição 70.

Bovet, D., \& Martha, J. (2001). Redes de valor. São Paulo: Atlas.

Chesbrough, H. (2003). Open innovation: the new imperative for creating and profiting from technology. Boston: Harvard Business School Press.

. (2007). Why companies should have open business model. MIT Sloan Management Review. v. 48, n.2, p.22-28.

Christensen, C.M., \& Raynor, M.E. (2003). The innovator solution: creating and sustaining successful growth. Boston (MA): Harvard Business School Press.

Davila, T., Epstein, M., \& Shelton, R. (2005). The art of innovation. Philadelphia (PA): Wharon School Publ., 2005.

Eisenhardt, K.M. Building Theories from Case Study Research. (1989). Academy of Management Review, v.14, no.4, p. 532-550. 
Hagel III, J. (2002). Out of the box. Boston: Harvard Business School Publ.

Hamel, G. (2000). Leading the revolution. Boston (MA): HBS Press.

Kelly, T., \& Littman, J. (2005). The ten faces of innovation. New York: Broadway Business.

Leifer, R., O’Connor, G.C., \& Rice, M. (2002). Implementação de inovação radical em empresas maduras. Revista de Administração de Empresas - RAE, v. 42, n.2, p.17-30.

Maital, S., \& Seshadri, D.V.R. (2007). Innovation management: strategies, concepts and tools for growth and profit. New Delhi: Response Book.

Schumpeter, J.A. (1961). The theory of economic development. Nova York: Oxford University.

Skarzinski, P., \& Gibson, R. (2008). Innovation to the core. Boston (MA): HBS Press.

Recebido: 28/02/2013

Aprovado: 21/04/2013 